\title{
Gingival Presentation of Verrucous Carcinoma- A Rare Case
}

\author{
Deeksha Mehta ${ }^{1}$, Shalini Kapoor ${ }^{2}$, Amit Bhardwaj $^{3}$ \\ ${ }^{1}$ Department of Periodontology, Faculty of Dental Sciences, SGT University, Gurugram, Haryana, India. ${ }^{2}$ Department of \\ Periodontology, Faculty of Dental Sciences, SGT University, Gurugram, Haryana, India. ${ }^{3}$ Department of \\ Periodontology, Faculty of Dental Sciences, SGT University, Gurugram, Haryana, India.
}

\section{INTRODUCTION}

Verrucous carcinoma also known as Ackerman's tumour is a variant of well differentiated squamous cell carcinoma that affects cutaneous and mucosal surfaces. Ackerman's tumour accounts for $1-10 \%$ of cases of Squamous Cell Carcinoma in the epithelial lining of oral mucosa and gingiva. It appears as slowly enlarging warty, exophytic cauliflower like overgrowth, grey or white in colour and is seen commonly in older males. ${ }^{1}$ Tobacco consumption has been the primary aetiology of verrucous carcinoma. . $^{2,3}$ The oncogenic viruses HPV 16 and 18 are also implicated in the aetiology of this condition. ${ }^{4}$ Other etiological factors may include smoking, poor hygiene and alcohol abuse. Verrucous carcinoma shows typical clinical behaviour being locally invasive. The rate of nodal metastasis is less, neck dissection and radiotherapy are the least opted modalities for treatment. The treatment of this is usually surgical excision and prognosis is fair. In this paper we report a typical gingival presentation of verrucous carcinoma bilaterally along with the clinicopathological diagnosis and a review of scientific literature.

Verrucous carcinoma also known as Ackerman's tumour is a variant of well differentiated squamous cell carcinoma that affects cutaneous and mucosal surfaces. It accounts for $1-10 \%$ of cases of Squamous Cell Carcinoma in the epithelial lining of oral mucosa or gingiva. Tobacco consumption has been the primary aetiology of verrucous carcinoma. Other etiological factors may include oncogenic viruses HPV 16 and 18, smoking, poor hygiene and alcohol abuse. Verrucous carcinoma shows typical clinical behaviour being locally invasive. In this paper we report a typical gingival presentation of verrucous carcinoma bilaterally in a 40 year old male patient along with the clinicopathological diagnosis, review of scientific literature and treatment aspect.

\section{PRESENTATION OF CASE}

A 40-year-old male patient came to the Department of Periodontology with the chief complaint of a growth on left lower back tooth region since 1 year. The patient gave history of chewing gutkha 1 packet daily from last 8-9 years. He stopped chewing it from last 2 months. The medical history of the patient revealed that he was diabetic and was on medication for diabetes since 3 years. There were no extraoral findings (non-palpable, non-tender lymph nodes with no swelling present). (Figure 1).
Corresponding Author: Dr. Shalini Kapoor,

Reader,

Department of Periodontology,

Faculty of Dental Sciences, SGT University, Gurugram, Haryana, India.

E-mail:dr_shalinibasur@yahoo.co.in

\section{DOI: $10.14260 / j e m d s / 2020 / 343$}

Financial or Other Competing Interests: None.

How to Cite This Article:

Mehta D, Kapoor S, Bhardwaj A.Gingival presentation of verrucous carcinoma- a rare case. J. Evolution Med. Dent. Sci. 2020;9(19):1572-1574,

10.14260/jemds/2020/343

Submission 27-02-2020,

Peer Review 24-04-2020,

Acceptance 30-04-2020,

Published 11-05-2020.

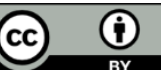




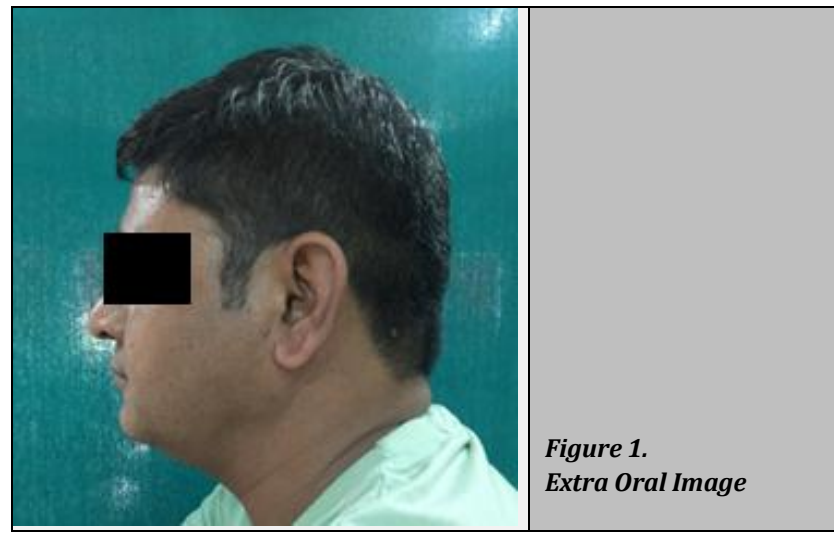

On clinical examination left lower vestibule area reveals an exophytic growth, sessile in nature, mixed red and white growth extending from distal surface of 35 to mesial surface of 38 present in the region of attached gingiva with a broad base, $3 \times 1 \mathrm{~cm}$ in diameter (Figure 2).

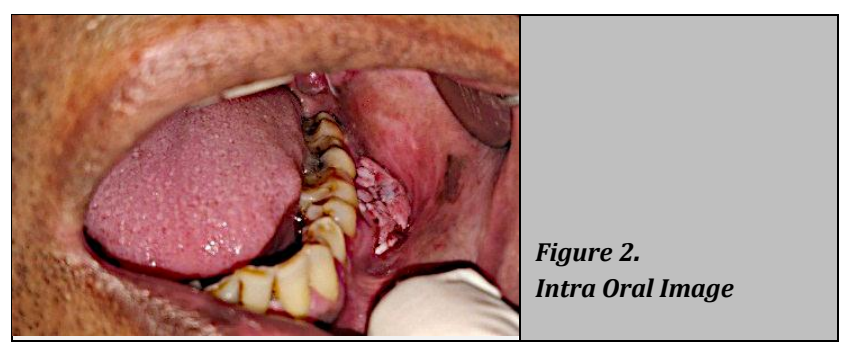

The surface appeared irregular, lobulated with small rounded projections. It was roughly ovoid in shape. On palpation the growth was non-tender and non-palpable with non-indurated margins, firm in consistency. It had a rough surface and did not bleed on manipulation. Right lower buccal vestibule reveals a whitish patch extending from mesial of 35 to distal of 37 in the region of attached gingiva with a diameter of approximately $2.5 \times 1 \mathrm{~cm}$.

\section{CLINICAL DIAGNOSIS}

Verrucous Hyperplasia

\section{DIFFERENTIAL DIAGNOSIS}

1. Papilloma

2. Pseudoepitheliomatous Hyperplasia

3. Verrucous Hyperplasia

4. Squamous Cell Carcinoma

\section{PATHOLOGICAL DISCUSSION}

Patient was advised routine histopathologic examination. However, the report was non-contributory. Hence the patient was advised incisional biopsy to confirm the diagnosis.

\section{Histopathological Features}

Epithelium is stratified squamous and exhibits bullous rete ridges. Acanthosis and keratin plugging can be seen. In some areas, epithelium exhibits basal cell hyperplasia, nuclear hyperchromatism and cellular pleomorphism. Underlying connective tissue is minimal and exhibits dense collagen fibres, dense inflammatory cell infiltrate, blood vessels, extravasated RBCs (Figure 4). All these features are suggestive of Verrucous Carcinoma.

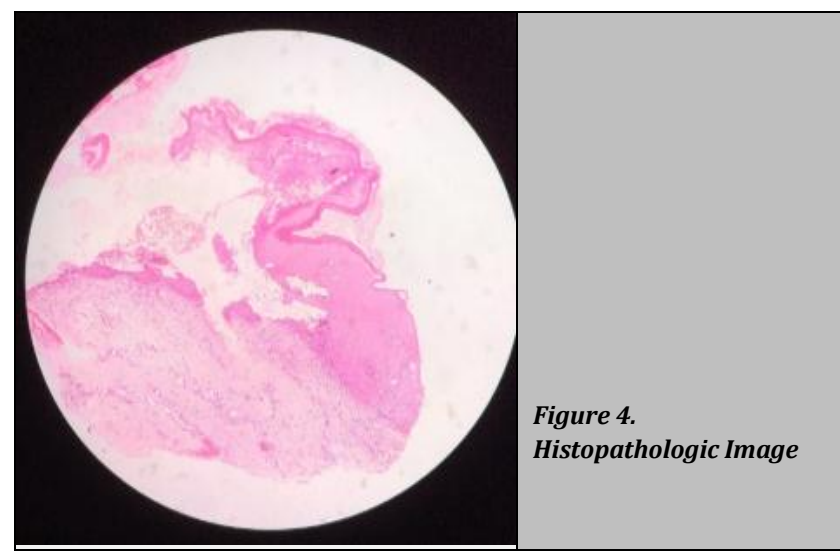

The treatment includes wide excision of the carcinomatous lesion including $1 \mathrm{~mm}$ of normal marginal tissue and reconstruction by buccal fat pad followed by intraoral suturing by the department of Oral Surgery and anaesthesia.

\section{DISCUSSION}

The first ever documented evidence of a verrucous carcinoma dates back to 1941 when Fridell and Rosenthal reported a case of a well differentiated squamous cell carcinoma of the oral cavity as "papillary verrucous carcinoma." It was described by Ackerman in 1948 as a variant of oral carcinoma and was subsequently reported from the penis, vulva, respiratory mucosa and various cutaneous sites. Most commonly it is present on the buccal mucosa or gingiva. It has been described as respiratory involving the oral cavity, oesophagus and upper respiratory mucosa (corresponding to 'oral florid papillomatosis'), genito-gluteal (earlier described as Bushcke and Lowenstein tumour) and plantar (epithelioma cuniculatum). ${ }^{5}$ The course of the tumour is usually indolent with extensive local destruction of tissues. $6,7,8$ Verrucous carcinoma is a slow growing lesion with exophytic growth pattern and predilection for males from fourth to sixth decade which becomes locally invasive if not treated properly. Rare regional lymph node metastases and distant metastases have not been reported ${ }^{9}$. Betel nut chewing, poor dental hygiene and human papillomavirus infection have been implicated in the development of verrucous carcinoma. In India approximately $7 \%$ of the oral cancers are verrucous carcinoma. ${ }^{10}$ 


\section{CONCLUSIONS}

Verrucous carcinoma of the oral cavity has varied clinical presentation. The rate of malignant transformation to squamous cell carcinoma remains high. The mortality of verrucous carcinoma is due to local invasion rather than metastatic spread, thus patients with verrucous carcinoma have a favourable prognosis.

\section{REFERENCES}

[1] Spiro RH. Verrucous carcinoma, then and now. Am J Surg 1998;176(5):393-7.

[2] Ackerman LV.Verrucous carcinoma of the oral cavity. Surgery1948;23(4):670-8.

[3] Enriquez RE, Ciola B, Bahn SL. Verrucous carcinoma arising in an odontogenic cyst. Report of a case. Oral Surg Oral Med Oral Path 1980;49(2):151-6.

[4] Wolff K, Johnson RA, Suurmond D. Fitzpatrick's Color atlas and synopsis of clinical dermatology. $5^{\text {th }}$ edn. New York: McGraw-Hill Publishers 2005: p. 1025.
[5] Jerajani HR, Amladi ST. Skin tumours and lymphoproliferative disorders. In: Valia RG, Valia AR, eds. IADVL text book and atlas of dermatology. $2^{\text {nd }}$ ednMumbai: Bhalani Publishing House 2001: p. 11589.

[6] Kraus FT, Perezmesa C. Verrucous carcinoma. Clinical and pathologic study of 105 cases involving oral cavity, larynx and genitalia. Cancer 1966;19(1):26-38.

[7] Samitz MH, Ackerman AB, Lantis LR. Squamous cell carcinoma arising at the site of oral florid papillomatosis. Arch Dermatol 1967,96(3):286-9.

[8] Grinspan D, Abulafia J. Oral Florid papillomatosis (Verrucous Carcinoma). Int J Dermatol 1979;18(8):60822.

[9] Walvekar RR, Chaukar DA, Deshpande MS, et al. Verrucous carcinoma of the oral cavity: a clinical and pathological study of 101 cases. Oral Oncol 2009;45(1):47-51.

[10] Murti PR, Gupta PC, Bhonsle RB, et al. Smokeless tobacco use in India: effects on oral mucosa. In: Stotts RC, Schroeder KL, Burns DM, eds. Smokeless tobacco or health, an international perspective. Bethesda, Maryland: US Dept. Health Human Services (NIH). NIH Publ No. 923461; 1992: p. 51-65. 